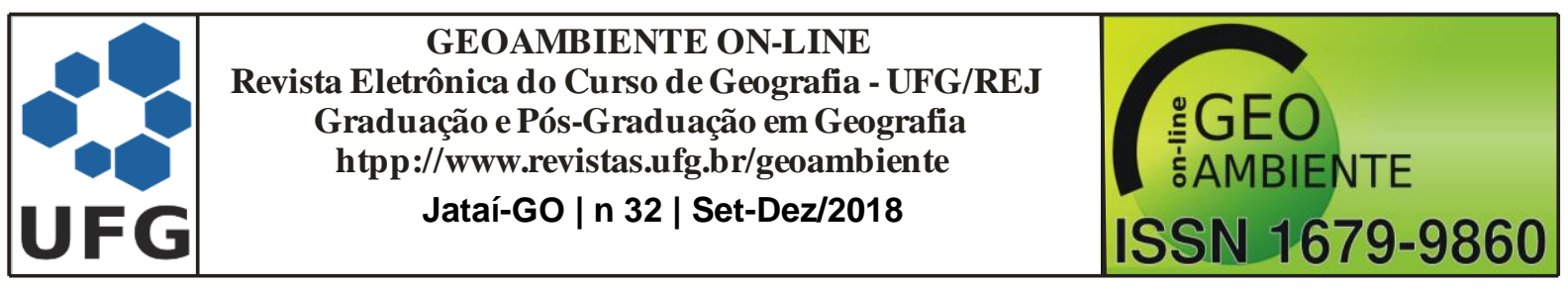

\title{
A UTILIZAÇÃO DE GEOTECNOLOGIAS E INTERNET NO FORTALECIMENTO TURÍSTICO DO MUNICÍPIO DE PRUDENTÓPOLIS, PR
}

Ronaldo Ferreira Maganhotto'; Leandro Baptista'; Claudio Shigueki Suzuki²; Vanessa

\begin{abstract}
Alberton $^{3}$
(1 - Universidade Estadual do Centro-Oeste - UNICENTRO, Doutor em Geografia e professor do curso de Bacharelado em Turismo, E-mail: ronaldomaganhotto@gmail.com; leandro.baptista@live.com; 2 - Universidade Estadual do Centro-Oeste - UNICENTRO, Doutor em Enfermagem em Saúde Pública e professor do curso de Licenciatura em Educação Física, E-mail: suzuki@unicentro.br; 3 - Mestre em Desenvolvimento Comunitário. E-mail: valbertontur@gmail.com).
\end{abstract}

Resumo: Cada vez mais, a promoção turística de um destino está atrelada à disponibilidade de ferramentas informativas e orientativas, vinculadas ao uso de geotecnologias, da tecnologia da informação e da internet. Assim, diante da necessidade de instrumentos que venham auxiliar o planejamento e execução de viagem ao destino turístico de Prudentópolis, Paraná, o qual apresenta peculiaridades naturais e culturais, o presente estudo teve como objetivo apresentar os procedimentos utilizados para a criação do site, folder e aplicativo, elaborados no Projeto "Roteiro Turístico no Meio Rural: uma alternativa não agrícola para complementação de renda das pequenas propriedades do Município de Prudentópolis", vinculado ao Programa Universidade Sem Fronteiras e à Universidade Estadual do CentroOeste - UNICENTRO. O projeto foi desenvolvido entre agosto de 2015 a setembro de 2016, por uma equipe interdisciplinar. O estudo, de caráter qualitativo, configurou-se como um estudo de caso, no qual a pesquisa bibliográfica, digital e de campo foram as técnicas utilizadas para a aquisição das informações; identificando os pontos de interesse turístico do município e a existência de meios digitais relacionados. Na segunda etapa, o Sistema de Posicionamento Global (GPS) foi utilizado para proceder a localização geográfica e o percurso de acesso aos pontos turísticos. Tendo por base tais informações, passou-se à criação do site, folder e aplicativo IPrudi. Tais produtos gerados têm contribuído para o

Artigo recebido para publicação em 15 de outubro de 2017

Artigo aprovado para publicação em 05 de setembro de 2018 


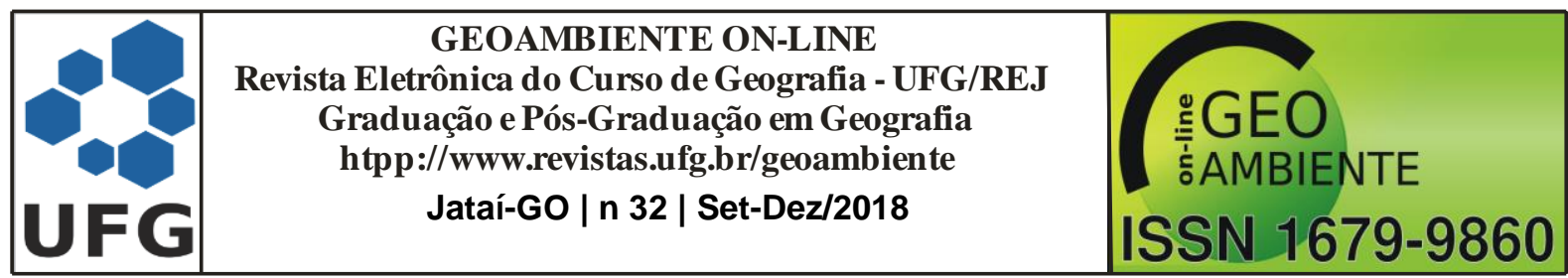

desenvolvimento turístico do município, além de servir como modelo para novas iniciativas do poder público e privado, que almejam alavancar a atividade turística da região.

Palavras-chave: Geotecnologia; Turismo; Roteirização.

\section{THE USE OF GEOTECHNOLOGIES AND INTERNET IN THE TOURIST STRENGTHENING OF THE MUNIPALITY OF PRUDENTOPOLIS, PR}

Abstract: Increasingly, the tourist promotion of a destination is linked to the availability of informative and orientative tools, linked to the use of geotechnologies, information technology and the internet. Thus, in view of the need for instruments that will aid in the planning and execution of the trip to the tourist destination of Prudentópolis, Paraná, which presents natural and cultural peculiarities, the present study aimed to present the procedures used for the creation of the site, folder and application, elaborated in the Project "Tourism Route in the Rural Environment: a non-agricultural alternative for the supplementation of income of the small properties of the Municipality of Prudentópolis", linked to the University Without Borders Program and to the State University of the Center-West - UNICENTRO. The project was developed between August 2015 and September 2016 by an interdisciplinary team. The qualitative study was set up as a case study, in which the bibliographic, digital and field research were the techniques used to acquire the information; identifying the points of tourist interest of the municipality and the existence of related digital media. In the second stage, the Global Positioning System (GPS) was used to proceed the geographic location and access route to the tourist spots. Based on this information, the creation of the site, folder and IPrudi application was started. These products have contributed to the development of tourism in the municipality, as well as serving as a model for new public and private initiatives, which aim to leverage tourism activity in the region.

Keywords: Geotechnology; Tourism; Routes.

\section{EL USO DE GEOTECNOLOGÍAS E INTERNET EN EL FORTALECIMIENTO TURÍSTICO DEL MUNICIPIO DE PRUDENTÓPOLIS, PR}

Resumen: Cada vez más la promoción turística de un destino está relacionada a la disponibilidad de herramientas informativas $y$ orientativas, vinculadas al uso de geotecnologías, de la tecnología de la información y de la Internet. Así, ante la necesidad de 


\begin{tabular}{|c|c|c|}
\hline & $\begin{array}{c}\text { GEOAMBIENTE ON-LINE } \\
\text { Revista Eletrônica do Curso de Geografia - UFG/REJ } \\
\text { Graduação e Pós-Graduação em Geografia } \\
\text { htpp://www.revistas.ufg.br/geoambiente } \\
\text { Jataí-Go | n } 32 \text { | Set-Dez/2018 }\end{array}$ & $\begin{array}{c}\text { ISSN 1679-9860 } \\
\text { G }\end{array}$ \\
\hline
\end{tabular}

instrumentos que vengan a auxiliar la planificación y ejecución de viaje al destino turístico de Prudentópolis, Paraná, el cual presenta peculiaridades naturales y culturales, el presente estudio tuvo como objetivo presentar los procedimientos utilizados para la creación de un sitio, en el Proyecto "Ruta Turística en el Medio Rural: una alternativa no agrícola para complementación de renta de las pequeñas propiedades del Municipio de Prudentópolis", vinculado al Programa Universidad sin Fronteras de la Universidad Estadual del Centro-Oeste - UNICENTRO. El proyecto fue desarrollado entre agosto de 2015 y septiembre de 2016, por un equipo interdisciplinario. El estudio, de carácter cualitativo, se configuró como un estudio de caso, en el cual la investigación bibliográfica, digital y de campo fueron las técnicas utilizadas para la adquisición de las informaciones; identificando los puntos de interés turístico del municipio y la existencia de medios digitales relacionados. En la segunda etapa, el Sistema de Posicionamiento Global (GPS) fue utilizado para proceder la ubicación geográfica y el recorrido de acceso a los puntos turísticos. En base a esta información, se pasó a la creación del sitio, la carpeta y la aplicación IPrudi. Tales productos generados han contribuido al desarrollo turístico del municipio, además de servir como modelo para nuevas iniciativas del poder público y privado, que anhelan aprovechar la actividad turística de la región.

Palabras-clave: Geotecnología; Turismo; Ruteo.

\section{Introdução}

O turismo tem se mostrado em alguns municípios, especialmente em destinos indutores (BRASIL, s/d), como a principal atividade econômica que, além de gerar divisas, empregos diretos e indiretos, valoriza os recursos naturais e culturais do local, bem como promove melhoria à infraestrutura local.

Deste modo, o desenvolvimento desta atividade, além da manutenção das vias de acesso, a profissionalização das pessoas envolvidas, a criação e implementação de atrativos, deve proporcionar meios para a promoção turística do destino, bem como gerar ferramentas informativas e orientativas.

O município de Prudentópolis, localizado na região Centro Sul do Paraná, distante cerca de $200 \mathrm{Km}$ da capital do estado, Curitiba, apresenta peculiaridades naturais e culturais que lhe conferem uma aptidão turística. Pessoas de diferentes destinos visitam o município 


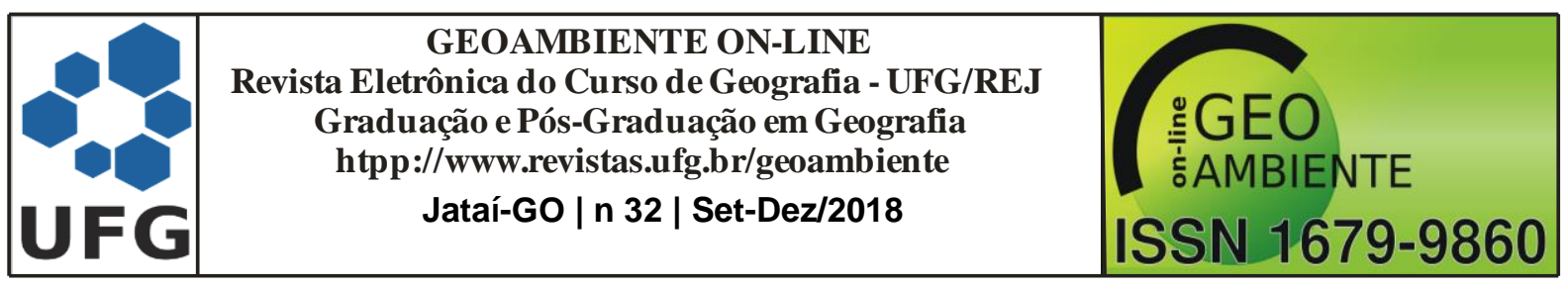

em busca de suas cachoeiras e demais aspectos rurais, da cultura ucraniana e de suas edificações religiosas. No entanto, em conversas com os visitantes e demais pessoas envolvidas na atividade turística constatou-se a necessidade de instrumentos auxiliares ao planejamento da viagem e a execução da mesma.

Neste contexto, o presente trabalho além de divulgar o site, o folder e o aplicativo elaborados no projeto Roteiro Turístico no Meio Rural: Uma Alternativa Não Agrícola para Complementação de Renda das Pequenas Propriedades do Município de Prudentópolis, vinculado ao Programa Estadual Universidade Sem Fronteiras e a Universidade Estadual do Centro-Oeste - UNICENTRO, objetiva apresentar os procedimentos utilizados para a criação dos mesmos.

A concretização destas ferramentas além de promover o município de Prudentópolis, tende a contribuir positivamente com os turistas, proprietários de atrativos, restaurantes e meios de hospedagem.

Desta feita, entende-se que ações como estas configuram-se como medidas necessárias ao fortalecimento da atividade turística em um determinado destino, uma vez que, além de elencar os produtos e serviços do município, facilitam a programação da viagem e a determinação dos percursos a serem realizados.

\section{O Uso de Geotecnologias e da Internet na Atividade Turística}

O uso das geotecnologias, da tecnologia da informação e da internet revolucionaram as relações nas últimas décadas. $\mathrm{O}$ acesso à internet facilitou a disseminação das informações e viabilizou a criação de diferentes ferramentas (sites, blogs, aplicativos e redes sociais) que repercutem diretamente nos destinos, atrativos e equipamentos turísticos.

Devido à quantidade de fluxos de informações que ocorrem na atividade turística, a aplicação de novas tecnologias é fundamental para que se possa dar melhor coordenação entre eles, o que permitirá desenvolver produtos turísticos de melhor qualidade (GÂNDARA, 2003, p. 165). Segundo Affolter (2003, p. 252), o turismo está sendo fortemente influenciado pelas tecnologias, que se torna um dos principais motores para estimular a competitividade.

Implementar essas novas tecnologias e fazê-las funcionar, com o comportamento do consumidor em constante mudança, demanda perícia e competência, assim como habilidade 


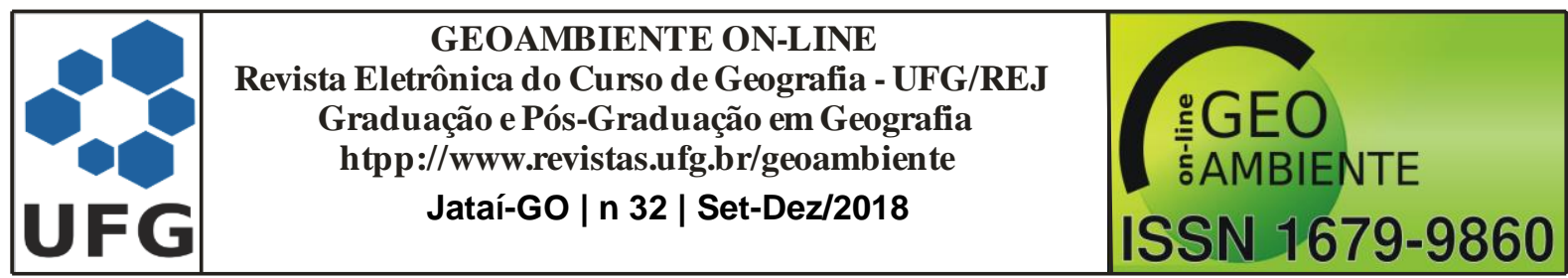

em combinar essas tecnologias com os requisitos com as peculiaridades dos negócios de viagens, destacando-se, sua intangibilidade.

Além de ampliar as ofertas e diminuir as distâncias, contribuindo para que as empresas turísticas ampliem suas atividades, reduzam custos e aumentem a sua competitividade, as novas tecnologias proporcionaram também o fortalecimento de Geotecnologias, direcionadas a espacialização de informações geográficas, configurando-se como um recurso imprescindível ao planejamento e gestão territorial, urbano e rural.

As geotecnologias (ou tecnologias espaciais), são consideradas o conjunto de técnicas que tem como função coletar, processar, analisar e oferecer informações com referência geográfica (ou espacial). Essas novas tecnologias estão ligadas aos avanços na informática, nas comunicações, nas geociências e em outras ciências correlatas. Os sistemas de informações geográficas, a cartografia digital, o sensoriamento remoto e o sistema de posicionamento global são exemplos de tecnologias espaciais. O emprego das Geotecnologias tende a contornar as carências de informações adequadas para subsidiar a avaliação, planejamento e monitoramento de questões ambientais, problemas urbanos e rurais. Além disso, o geoprocessamento apresenta um grande potencial, por basear-se em tecnologias de custo relativamente baixo, onde o conhecimento pode ser adquirido localmente (CÂMARA; DAVIS; MONTEIRO, 2001).

Os sistemas de informações geográficas, processados em ambiente de geoprocessamento, são capazes de revolucionar a forma como diferentes profissionais concebem e entendem o espaço, possibilitando a integração de informações de diferentes origens, formatos e fontes e a geração do resultado na forma de mapas. Os resultados podem ser diagnósticos, projeções, avaliações de impactos ou qualquer outra aplicação pretendida (WEBER; HASENACK, 1999).

Neste contexto, os produtos gerados em ambiente de geoprocessamento podem auxiliar a atividade turística em dois aspectos. Por um lado, configuram-se como uma ferramenta auxiliar ao planejamento turístico, por outro, podem vir a facilitar a programação do turista num determinado destino.

Os mapas turísticos possibilitam ao turista uma visão geral do espaço geográfico, com as informações que serão importantes para o planejamento das suas atividades de visitas e coordenação do seu tempo disponível. Tem por responsabilidade localizar o turista e permitir 


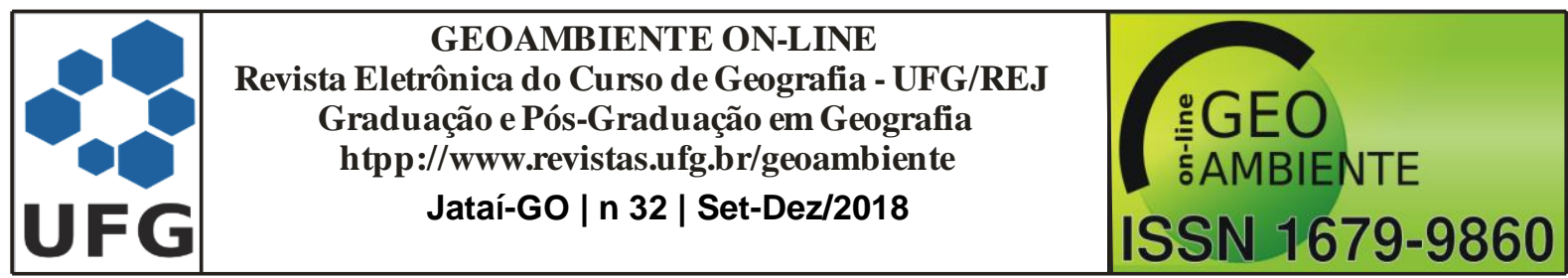

a localização de suas prioridades, respondendo as seguintes questões: "Onde estou?"; "Aonde vou?"; "Como vou?" e "Por onde vou?".

Diante deste cenário, com a popularização dos smartphones em todo o globo, o acesso e uso de aplicativos tornou-se uma atividade rotineira e de amplo conhecimento geral. Entre o amálgama de opções de aplicativos, destaca-se aqueles que são amparados em uma base de informações georreferenciadas, servindo por vezes, como uma ferramenta de apoio ao processo turístico.

Dentre estes, pode-se citar o Google Earth, ferramenta que já possui diversos estudos (PATTERSON, 2007; SHEPPARD; CIZEK, 2008) quanto a sua aplicabilidade para a compreensão e educação nas geociências, com especial interesse da Geografia por proporcionar a compreensão tangível de elementos como escala, território, espaço, região e lugar. No entanto, para este estudo a perspectiva que este software oferece enquanto técnica interpretativa relaciona-se a comunicação, localização e informação sobre os atrativos. Mesmo restringindo-se ao acesso gratuito do Google Earth, sua plataforma estimula o entretenimento e seu design favorece o autoaprendizado, características fundamentais para sua popularização.

De igual modo, o Google Maps serviu como uma base de dados off-line especialmente por contar com a independência de consulta: uma vez que as imagens no conjunto de dados são uniformemente distribuídas em diferentes locais, independentemente da popularidade de um determinado local ou objeto, a tarefa de localização é independente da popularidade dos objetos na imagem da consulta; precisão: à medida que as imagens no conjunto de dados possibilitam localizar corretamente uma imagem com um maior grau de precisão do que seria permitido por um conjunto de dados mais dispersos e; pela abrangência e a uniformidade do conjunto de dados necessitarem de uma localização precisa, sem empregar métodos baseados em geometria epipolar (ZAMIR; SHAH, 2010), elementos considerados essenciais para a produção do folder temático.

\section{Destinos turísticos inteligentes: não mais uma opção, uma necessidade}

A atual concepção de mundo pós-moderno (HALL, 1999) exige dos planejadores de destinos turísticos uma visão holística, que perpasse as teorias e modelos clássicos estruturantes (BENI, 2004; BOULLÓN, 2001), onde sejam diagnosticadas esferas de atuação 


\begin{tabular}{|c|c|c|}
\hline & $\begin{array}{c}\text { GEOAMBIENTE ON-LINE } \\
\text { Revista Eletrônica do Curso de Geografia - UFG/REJ } \\
\text { Graduação e Pós-Graduação em Geografia } \\
\text { htpp://www.revistas.ufg.br/geoambiente } \\
\text { Jataí-Go | n } 32 \text { | Set-Dez/2018 }\end{array}$ & $\begin{array}{c}\text { ISSN 1679-9860 } \\
\text { G }\end{array}$ \\
\hline
\end{tabular}

sobre os ambientes cultural, ambiental, social e econômico. Na contemporaneidade, a busca pela diferenciação no mercado, além de contemplar estas quatro vertentes, necessita ainda estar profundamente engajada com os conceitos de desenvolvimento sustentável e com a adoção de técnicas que permitem ao destino ser considerado como um Destino Turístico Inteligente, termo subsidiado das chamadas Cidades inteligentes (LAMSFUS et al, 2015).

Para tanto, as principais diferenças que segregam os conceitos referem-se ao nível de abrangência de uma cidade como um todo, para um destino de forma isolada. Enquanto as cidades têm preocupações como capital humano, participação, mobilidade e a qualidade de vida em seu sentido amplo, os destinos possuem territorialidades próprias, que não obedecem a limites políticos ou geográficos, preocupam-se mais com público-alvo (turistas) e as formas de interação destes com os moradores locais, ao se apoiar em três pilares: governança, tecnologia e desenvolvimento sustentável (SEBRAE, 2016).

Neste sentido, pode-se conceituar os destinos turísticos inteligentes enquanto:

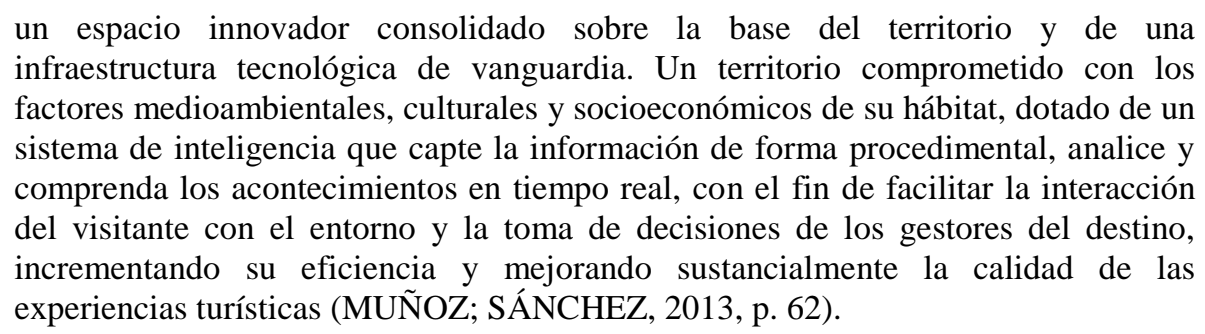

Como apresentado, esta gestão territorial se apresenta enquanto vanguarda, gerando assim, maiores desafios para sua efetiva implantação, estudos e análises. Contudo, algumas informações comuns (LAMSFUS et al, 2015; BUHALIS, AMARANGGANA; 2015) permitem considerar como elementos-chave a facilidade de locomoção dos visitantes e a retroalimentação constante para seus gestores, que possibilitam em primeiro caso, o aumento da satisfação dos visitantes e para o trade turístico, a tabulação de dados para a melhora de seus serviços ou produtos.

Para o SEBRAE (2016), as principais características dos destinos inteligentes estão vinculadas a nove princípios interconectados, a citar: possuem um espaço turístico inovador; dispõem de tecnologia de ponta; valorizam o capital humano; estão focados no desenvolvimento sustentável; sabem gerir os recursos de forma eficiente; garantem maior competitividade ao setor; possibilitam experiências de qualidade aos visitantes; são integrados e interativos e por fim; garantem a sustentabilidade. 


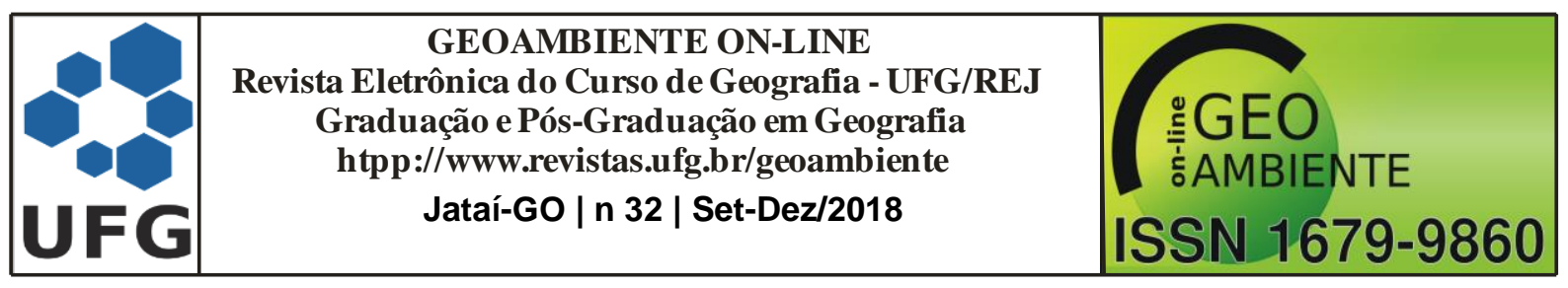

Ao analisar tais características, percebe-se que os pilares de governança, tecnologia e sustentabilidade são contemplados de forma a permitir o alcance de objetivos práticos, traçando metas estratégicas pontuais, como é o caso deste relato de experiência. Entende-se, contudo, que um projeto que parte da academia ao encontro de um destino turístico é incapaz de atender a todos os pré-requisitos, em função de suas limitações orçamentárias e, especialmente, políticas. Ainda assim, a valorização do capital humano (comunidade local), qualidade de experiência dos turistas e o desenvolvimento competitivo sustentável (equidade nas oportunidades à esfera privada) são elementos indispensáveis e atendidos, conforme será apresentado nos resultados deste artigo.

Cabe ainda a ressalva que o projeto foi aplicado no município de Prudentópolis, interior do Paraná, e que a localização geográfica da cidade está em consonância com Curitiba, capital do estado, considerada como a melhor cidade em termos de governança do Brasil e a segunda melhor em índices de qualidade do meio ambiente, categorias vitais para os destinos inteligentes (CONNECTED SMART CITIES, 2015). Assim, alinha-se ao exemplo de Curitiba e promove-se uma aproximação de gestão nos quesitos destaque da capital, somando-se à esfera tecnológica, de caráter inédito na região.

Por fim, o foco do projeto não reside essencialmente nos moradores da cidade, que em tese, já conhecem os atrativos disponíveis, seus acessos, cobrança ou não de ingressos, entre outras particularidades, mas que podem se beneficiar do produto enquanto uma ferramenta de divulgação, vinculado ao marketing local. Por sua vez, os visitantes, sejam por quaisquer motivações que se dirijam à cidade terão uma opção viável, gratuita e de fácil interatividade para alcançar suas expectativas e sanar eventuais dúvidas do destino.

Para tanto, inúmeras opções são viáveis para disponibilizar esta infraestrutura aos visitantes, como totens interativos, automatização de ingressos, óculos de realidade aumentada e virtual, sites específicos e aplicativos, são alguns dos mais comuns. Neste sentido, compreendendo o progressivo crescimento de vendas e utilização de smartphones, o próximo subcapítulo procura destacar algumas das características deste aparelho com fins de aplicação para os destinos turísticos inteligentes.

\section{Recursos de bolso: informação nas pontas dos dedos}




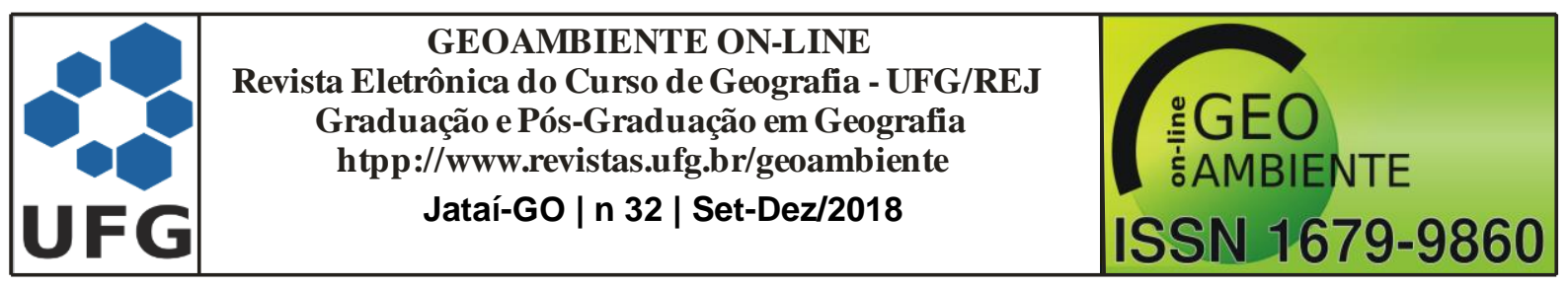

A venda de smartphones em todo o mundo vem provocando um crescimento exponencial do uso destes aparelhos para diversos fins, seja para pesquisar preços, procurar por opiniões sobre produtos e mais recentemente, vem substituindo gradativamente o uso de outros recursos, por estarem mais tempo disponível com as pessoas.

Diniz (2010) destaca que até mesmo a agricultura vem ganhando recursos através dos telefones móveis, uma vez que recebem a previsão de geadas. Em Salvador, durante o carnaval, pode-se acompanhar os trios elétricos por meio de smartphones. Estas características demonstram que o aparelho passou a cumprir inúmeras funções.

O potencial deste mercado para o turismo é visto como uma das principais tendências que afetarão a forma de se viajar, além de provocar um aumento no acesso de sites de empresas ou serviços turísticos, como hotéis, locadoras de veículos e parques de diversões através deste aparelho (HOSTELTUR, 2013).

Portanto, percebe-se que os aplicativos agregam valor ao turismo. Por exemplo, os QR Codes (Quick Response Code), bastante comuns em publicações ou mesmo em outdoors podem trazer consigo descontos ou promoções que somente estão disponíveis a partir deste meio. Outras oportunidades, como os aplicativos podem ser criados com as mais variadas funções, sendo oferecidos de forma gratuita ao amplo público.

Exemplos desta aplicabilidade são vistas em todas as partes do mundo, como Barcelona (país que em 2012 iniciou as discussões sobre os destinos turísticos inteligentes), onde um aplicativo oferece curiosidades sob a cidade, uso de Snapchat oficiais de órgãos que publicam suas novidades (como um museu ao inaugurar uma nova exposição), além de atendimentos personalizados por meio de recursos de conversas online tradicionais.

A possibilidade de transversalidade desta ferramenta é destacada em um cenário cada vez menos abstrato e fictício para uma realidade que muitas pessoas já experimentaram ou devem experimentar tão logo, onde Wang e Xiang (2012) descrevem uma “imaginação”, onde uma pessoa viaja por uma estrada qualquer dos EUA, utilizando como auxílio um GPS instalado no seu celular, que ao mesmo tempo executa as suas músicas favoritas, localizações de restaurantes favoritos próximos são constantemente destacados no mapa, seu roteiro é compartilhado em tempo real com amigos, que podem inclusive dar dicas do que se fazer naquele local. 


\begin{tabular}{|c|c|c|}
\hline & $\begin{array}{c}\text { GEOAMBIENTE ON-LINE } \\
\text { Revista Eletrônica do Curso de Geografia - UFG/REJ } \\
\text { Graduação e Pós-Graduação em Geografia } \\
\text { htpp://www.revistas.ufg.br/geoambiente } \\
\text { Jataí-Go | n } 32 \text { | Set-Dez/2018 }\end{array}$ & $\begin{array}{c}\text { :GEO } \\
\text { JEAMBIENTE } \\
\text { G }\end{array}$ \\
\hline
\end{tabular}

Todas estas situações são possíveis na atualidade, em praticamente todo o globo. A conexão via $4 \mathrm{G}$ ou $3 \mathrm{G}$ está disponível em qualquer área com cobertura de dados de voz, e vem sendo preferencial a chamadas convencionais. Afinal, é mais fácil comunicar-se com um grupo de pessoas ao enviar uma única mensagem do que replicá-la inúmeras vezes para cada pessoa que deseja informar. Além de experiências de lazer, como o foco deste estudo, o mesmo também se aplica para situações emergenciais, onde um simples "login" em redes sociais é interpretada como um sinal de que o visitante chegou ao destino, tranquilizando familiares em caso de acidentes aéreos ou terrestres.

\section{Caracterização da Atividade Turística no Município de Prudentópolis e a Utilização das}

\section{Geotecnologias e Internet para Promoção Turística do Município}

O município de Prudentópolis (Figura 1) está localizado na região Centro - Sul do estado do Paraná, às margens da BR 373 localizada entre Ponta Grossa e Guarapuava, com acesso também pela BR 277, a 203 km da cidade de Curitiba, capital do estado do Paraná. De acordo com o website Tribuna Paraná (2008), o município se destaca pelas suas belezas naturais, apresentando mais de 100 cachoeiras catalogadas, sendo que várias possuem mais de $100 \mathrm{~m}$ de altura.

Figura 1 - Localização do município de Prudentópolis

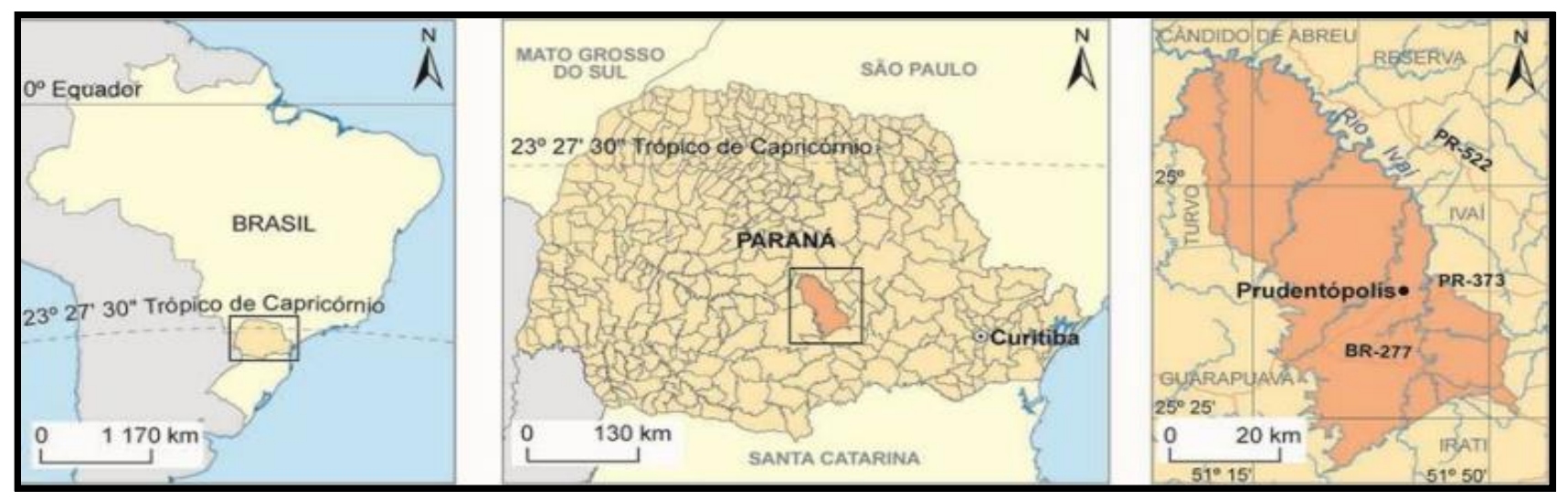

Fonte: IBGE (2005, apud SILVA e GÂNDARA, 2014)

De acordo com o website da Prefeitura de Prudentópolis, destacam-se o Cânion Barra Bonita com 3 quedas d'água, o RPPN - Ninho do Corvo com 8 quedas d'água, o Salto Barão do Rio Branco, os Saltos Gêmeos, o Salto Jacutinga, o Salto Manduri (também conhecido 


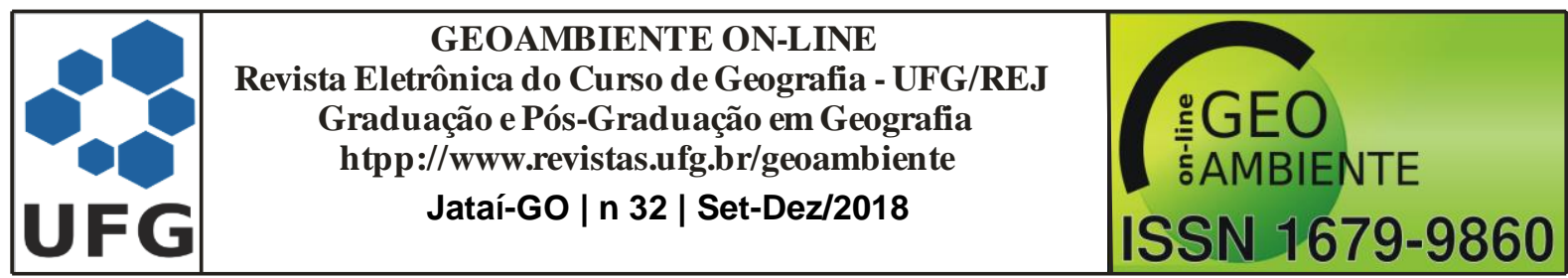

como Salto Rickli), o Salto São Sebastião, os Saltos Mlot e Cachoeira do Miguel (com 120 e 5 metros respectivamente), Salto São Francisco (o maior do sul do Brasil, com 195 metros de queda), o Salto São João e o Salto Sete.

O município despertou para o turismo na década de 1990, quando publicações de abrangência nacional levam o município a ser chamado de "Terra das Cachoeiras Gigantes". Com a crescente chegada de turistas, aparecem os primeiros condutores de turismo, em grupos organizados" (PREFEITURA MUNICIPAL DE PRUDENTÓPOLIS, 2015). Consequentemente, foram inaugurados diversos empreendimentos relacionados ao setor, tais como hotéis, pousadas, restaurantes, agências de turismo entre outros.

Motivados pela esperança de ter no turismo uma fonte de renda ainda maior, a comunidade empreendedora do município trabalha no sentido de ampliar a oferta dos produtos e serviços ofertados aos turistas. Diversos são os projetos e iniciativas desenvolvidas em parceria com instituições de ensino da região, Secretaria de Turismo e empreendimentos.

Atualmente, o turismo local conta com ferramentas da internet para auxiliar no marketing dos diversos segmentos praticados no município. É possível encontrar informações no meio digital, principalmente através de sites de busca como google, youtube e tripadvisor. Os empreendimentos relacionados às áreas naturais são os que mais se destacam em quantidades de publicações e também em organização de suas próprias formas de marketing, pois empreendimentos como RPPN Ninho do Corvo, Salto Sete Ecoturismo e Aventura, Recanto Perehouski, Salto São Sebastião e Pousada São João possuem site e/ou página em rede social, divulgando seus atrativos e compartilhando as experiências obtidas com os turistas.

A rede hoteleira se destaca em menores proporções na mídia social, sendo possível encontrar diversos alguns sites próprios, páginas em rede social e disponibilização de reservas via booking, submarino e trivago. E menor escala, é possível encontrar informações referentes a segmentos do turismo como o religioso, o cultural e o gastronômico, com publicações e reportagens acerca de igrejas, festas religiosas, grupos folclóricos, peças artesanais e alguns pratos típicos.

São desenvolvidas diversas pesquisas acadêmicas envolvendo o turismo no município de Prudentópolis, muitas delas realizando mapeamentos georreferenciados, aproximando o 


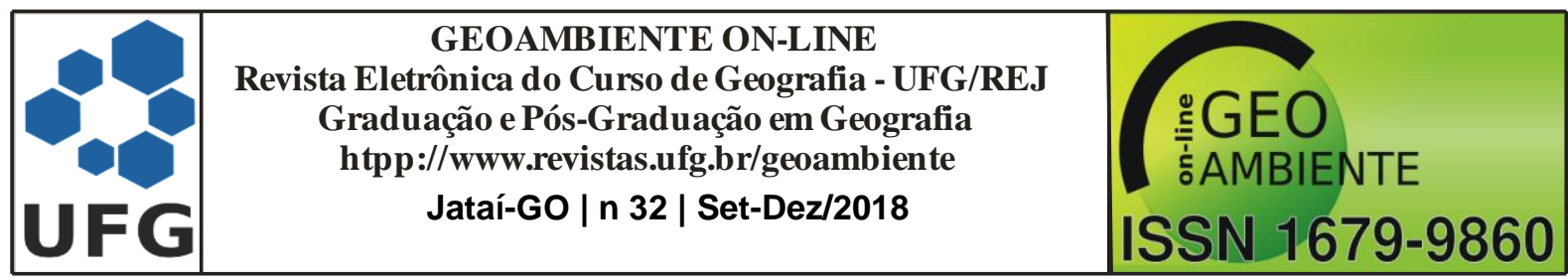

turista dos atrativos. Essas pesquisas são facilmente encontradas em sites de busca, se classificando como fontes de divulgação do turismo local.

\section{Procedimentos Metodológicos}

A presente pesquisa, de caráter qualitativo, configurou-se como um estudo de caso, onde a pesquisa bibliográfica, digital e de campo foram as técnicas utilizadas para a aquisição das informações.

A pesquisa bibliográfica orientou e fundamentou a elaboração destes produtos como ferramentas importantes à promoção turística do município. Nesta etapa, utilizou-se os seguintes autores Lamsfus (2015) e Buhalis; Amaranggana (2015) que tratam de destinos turísticos inteligentes, além de Diniz (2015) e Wang; Xiang (2012), que analisam o uso de aplicativos para smartphones no âmbito da atividade turística.

A pesquisa documental e digital serviu de base para identificar os pontos de interesse turístico do município e a existência de meios digitais relacionando os mesmos. Para isto utilizou-se do inventário turístico municipal e de sites de busca.

De posse dos pontos de interesse, os quais englobam os atrativos, centro de informações, empreendimento de hospedagem, de alimentação e outros, realizou-se um trabalho de campo, com intuito de coletar, com auxílio do Sistema de Posicionamento Glogal (GPS), a localização geográfica dos mesmos, bem como, o percurso de acesso. Estes foram transferidos para ambiente de geoprocessamento, onde foram editadas com intuito da elaboração da base cartográfica. Garmim Map Source, Spring e Corel Draw, foram os softwares utilizados para a transferência, processamento e edição dos dados.

Após esse levantamento, foi iniciado o planejamento e posterior desenvolvimento de website, folder turístico e aplicativo para smartphones. A intenção da criação deste conjunto de ferramentas se valeu da prerrogativa em proporcionar acessibilidade a um amplo público, ou seja, àqueles que preferem utilizar computadores convencionais; outros que optam por smartphones e/ou tablets e ainda os visitantes que se sentem mais confortáveis em ter fisicamente um material em mãos.

Para o website, as informações dos atrativos foram organizadas em quatro eixos (cultura, natureza, religiosidade e fé e rural). Enquanto, as referentes a hospedagem, alimentação, artesanatos, condutores e guisa turísticos e de utilidade pública encontram-se 


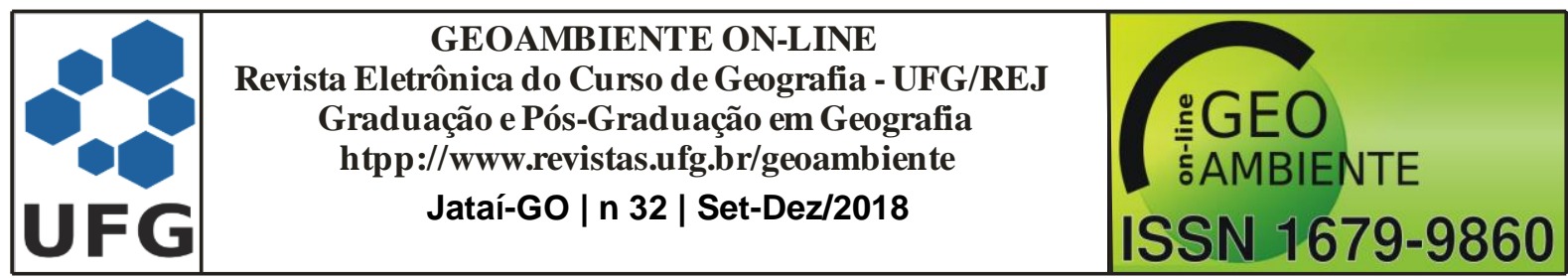

vinculadas ao item serviços. Estas informações, levantadas via consulta documental e meio digital foram organizadas utilizando-se da plataforma WIX, no endereço www.wix.com, disponibilizada de forma gratuita aos usuários.

Optou-se por desenvolvê-lo de modo responsivo (auto adaptável para acesso por meio de recursos móveis) e em plataformas que facilitem sua posterior atualização, uma vez que o projeto tem como foco a implantação dos recursos, cabendo aos integrantes do trade municipal, modificações futuras.

Em relação ao folder, apesar de estarem limitados ao conteúdo impresso, optou-se por destacar os principais atrativos, com fotos e curtos textos; e o Mapa Turístico, apresentando a disposição espacial dos atrativos localizados na área rural do município. Além destes elementos, também foram adicionados telefones úteis e um texto explicativo informando o programa ao qual estes materiais estavam atrelados. Para alcançar estes resultados, além dos dados obtidos com as pesquisas de gabinete, utilizou-se de saídas a campo para fotografar os atrativos, análise documental para produção de textos informativos e coleta de dados primários para atualização das informações de contato, bem como dos traçados e percursos realizados por meio de GPS.Após a organização das informações textuais no word e das informações cartográficas no SPRING, as mesmas foram exportadas para o Corel Draw, onde realizou-se a edição final.

Por fim, foi iniciado o desenvolvimento do aplicativo, onde optou-se pela abordagem de Entrega Incremental, onde são definidos conjuntos de funcionalidades e aos mesmos são atribuídas prioridades. Constroem-se então versões executáveis do software que são entregues para o cliente, que assim pode utilizá-las para familiarizar-se com o software e identificar novos requisitos (SOMMERVILLE, 2011).

Além disso, como são desenvolvidos inicialmente as funcionalidades mais importantes, estas passam por um maior número de testes, as quais estarão presentes na maioria das versões entregues. O processo ditado pela Entrega Incremental é exibido na Figura 2.

O processo de desenvolvimento foi então iniciado pela definição do esboço dos requisitos. Inicialmente, entendendo que o aplicativo deveria atuar como uma ferramenta de suporte aos turistas em Prudentópolis, por meio da apresentação e indicação dos atrativos e serviços atrelados ao turismo, atribuindo-se, assim, ao primeiro incremento. 


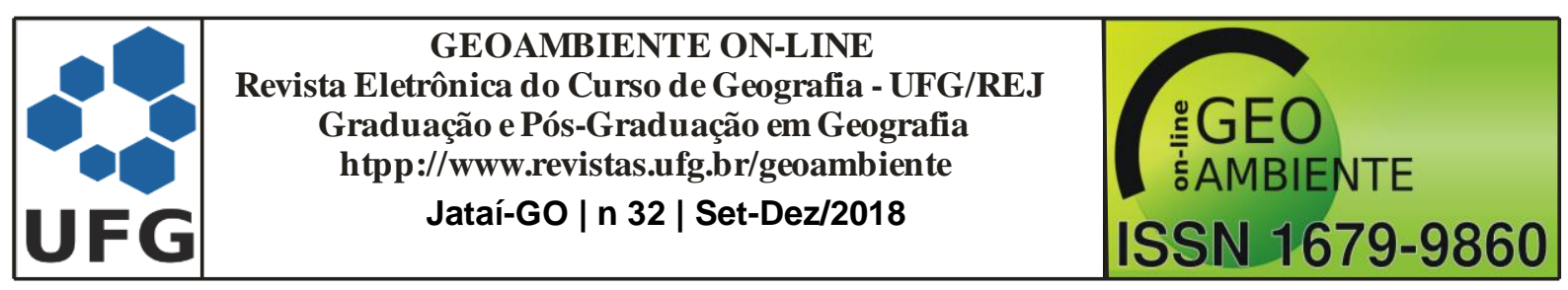

A partir da definição que a ferramenta desenvolvida seria na forma de um aplicativo para dispositivos móveis, dada a necessidade de mobilidade inerente das atividades turísticas, bem como da importância do turista identificar sua localização e o caminho até determinado ponto de interesse (atrativo, hotel, restaurante).

Figura 2 - Metodologia de desenvolvimento de software Entrega Incremental

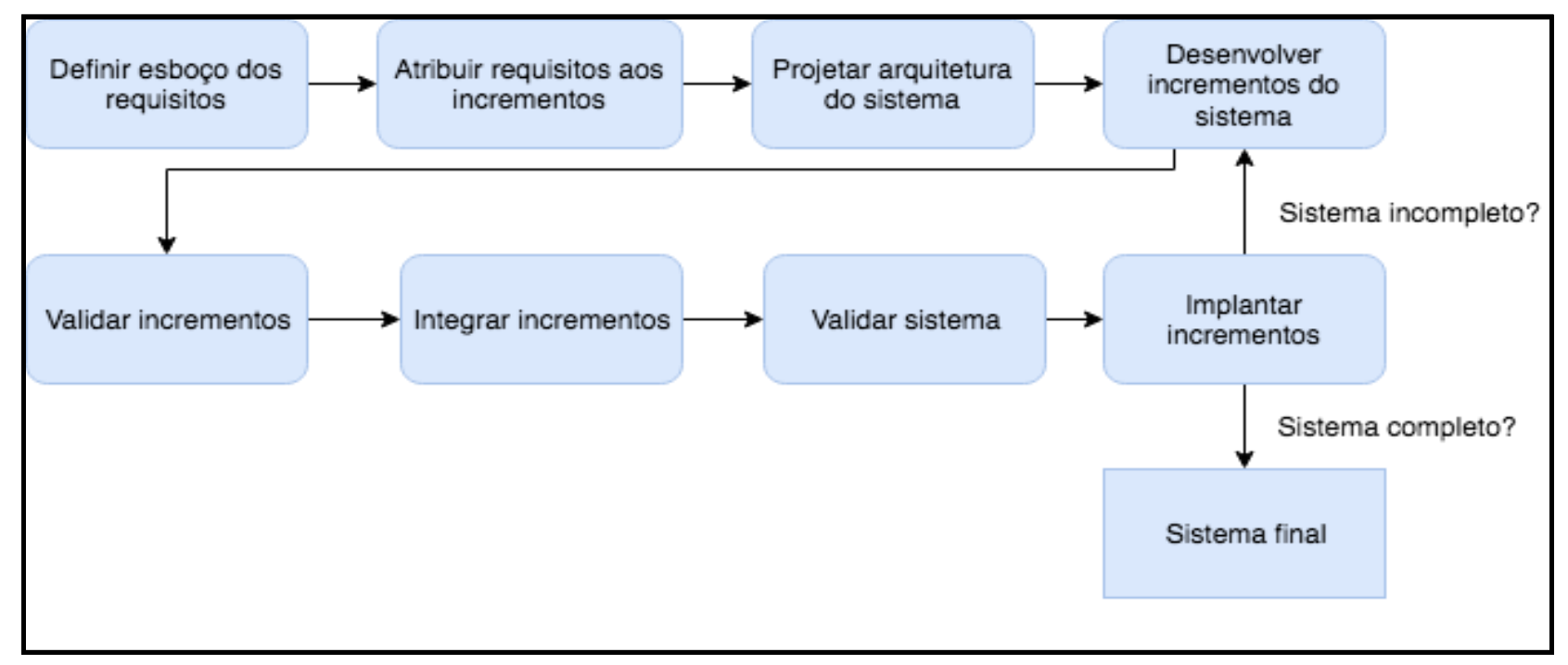

Fonte: Sommerville, 2011.

Neste contexto, partiu-se para a escolha da plataforma de desenvolvimento, sendo ela o Android (ANDROID STUDIO, 2017), sistema operacional desenvolvido pela Google, executado em uma vasta variedade de aparelhos do tipo smartphone e compatível com o aplicativo google maps, o qual possibilita a indicação da localização do usuário e rota a ser utilizada até o ponto de interesse do usuário (turista).

Definido estas questões o sistema foi alimentado com as informações textuais, digitais e localização geográfica (coordenadas geográficas) de cada ponto de interesse, os quais, também, foram adicionados ao website e ao folder.

Para a implementação do aplicativo foi empregado o ambiente de desenvolvimento integrado Android Studio, que conta com diversas ferramentas facilitadoras do processo de implementação. Entre elas:

- Editor inteligente de códigos: oferece sugestões, refatoração e análise de código;

- Possui emulador integrado, para que não seja necessário possuir um smartphone com o sistema Android para testes; 


\begin{tabular}{|c|c|c|}
\hline & $\begin{array}{c}\text { GEOAMBIENTE ON-LINE } \\
\text { Revista Eletrônica do Curso de Geografia - UFG/REJ } \\
\text { Graduação e Pós-Graduação em Geografia } \\
\text { htpp://www.revistas.ufg.br/geoambiente } \\
\text { Jataí-Go | n } 32 \text { | Set-Dez/2018 }\end{array}$ & $\begin{array}{c}\text { ISSN 1679-9860 } \\
\text { G }\end{array}$ \\
\hline
\end{tabular}

- Funcionalidade "Instant Run", que permite executar automaticamente no emulador um aplicativo cujo código foi alterado.

A interface do ambiente é dividida de acordo com o exibido na Figura 3, a saber: (1) A barra de ferramentas permite desempenhar várias ações, como executar o aplicativo e utilizar ferramentas do Android; (2) A barra de navegação auxilia na navegação através do projeto e abre arquivos para edição; (3) A janela de edição é onde o código é criado e modificado. $\mathrm{O}$ editor adapta-se ao tipo do arquivo atual; (4) A barra de ferramenta de janela é executada ao redor da janela do ambiente e contém botões que permitem expandir ou minimizar janelas de ferramentas individuais; (5) A janela de ferramentas dá acesso a tarefas específicas como gerenciamento de projetos, pesquisa, controle de versões, etc; (6) A barra de status mostra o estado do projeto e do ambiente em si, bem como outros avisos e mensagens.

Figura 3: Tela de programação do aplicativo

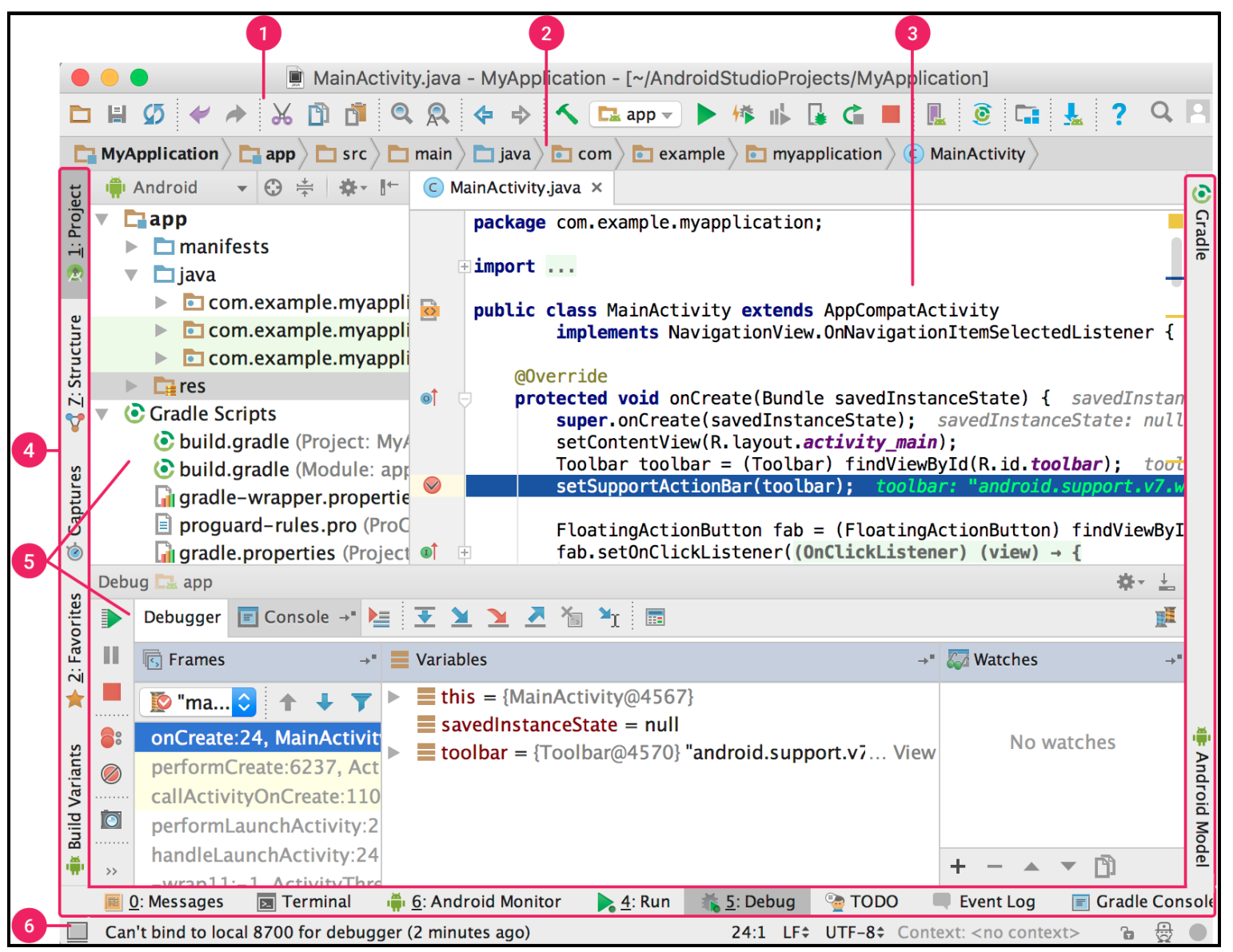

Fonte: https://developer.android.com/studio/intro/index.html, 2017. 


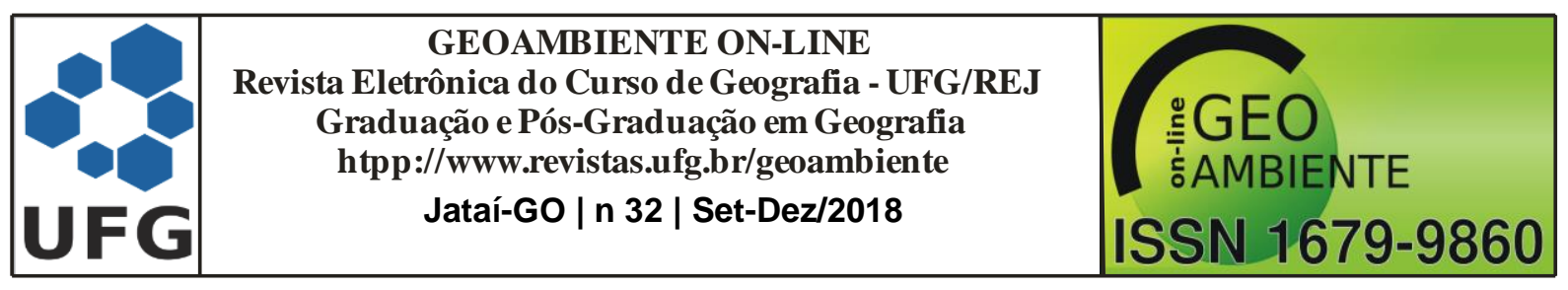

\section{Resultados e Discussão}

\section{Website: uma ferramenta de divulgação}

Os sites tornaram-se ferramenta indispensável à atividade turística, servem como meios de informação, promoção e comercialização. Neste contexto, a equipe do projeto de extensão elaborou para Prudentópolis um site informativo. Este tende a auxiliar o turista em sua programação de viagem, uma vez que, apresenta além dos atrativos turísticos (naturais, culturais e religiosos) os meios de hospedagem, estabelecimentos alimentícios, artesanatos e presentes, condutores e guias e de utilidade pública.

$\mathrm{O}$ endereço do site encontra-se na plataforma wix no seguinte endereço http://roteiroprudentopolis.wixsite.com/iprudi, a plataforma é gratuita, no entanto, sua visibilidade e engajamento são questionáveis, fato que há de se avaliar. O website apresenta o conteúdo mais completo em relação às demais ferramentas, uma vez que sua navegação, familiaridade e capacidade de interação destacam-se frente a outras estratégias informativas. A Figura 4 apresenta o layout do site.

Figura 4: Layout da página inicial do site

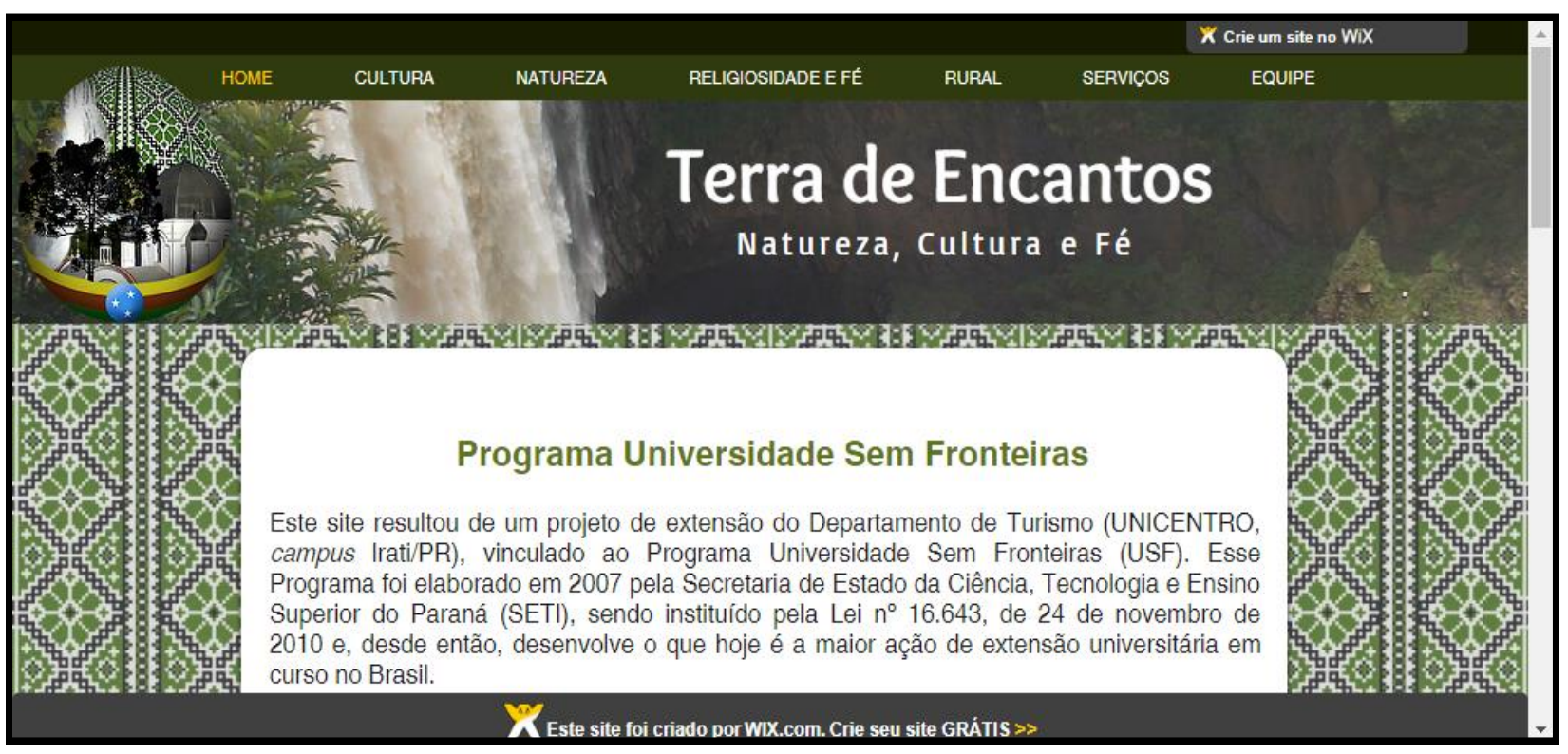

Fonte: http://roteiroprudentopolis.wixsite.com/iprudi, 2017.

A plataforma wix oferece diversos templates que podem ser utilizados pelo usuário, não necessitando conhecimentos avançados para seu manuseio. Além de ser de fácil edição, 


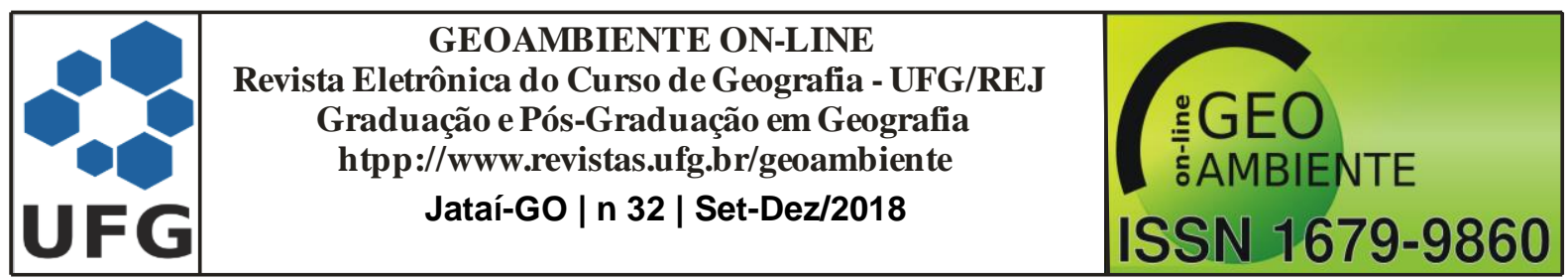

permite a visualização do site mobile, possibilitando que o usuário tenha acesso à versão do site adaptada para a tela do celular.

\section{Folder turístico: material de apoio de campo}

O município dispunha de figuras auxiliares ao deslocamento para fins turísticos. Ao avaliá-las verificou-se que a inexistência de coordenadas, escalas, legenda e signos apropriados podem vir a comprometer o deslocamento dos visitantes em Prudentópolis. Assim, a elaboração do folder turístico com informações textuais (mesmo conteúdo do site) e a espacialização dos atrativos turísticos configurou-se como um instrumento facilitador da visita, facultando a respostas das seguintes questões: Onde estou? Onde vou? Por onde vou? A que distância estou? A Figura 5 apresenta este material.

Figura 5: Parte informativa do folder

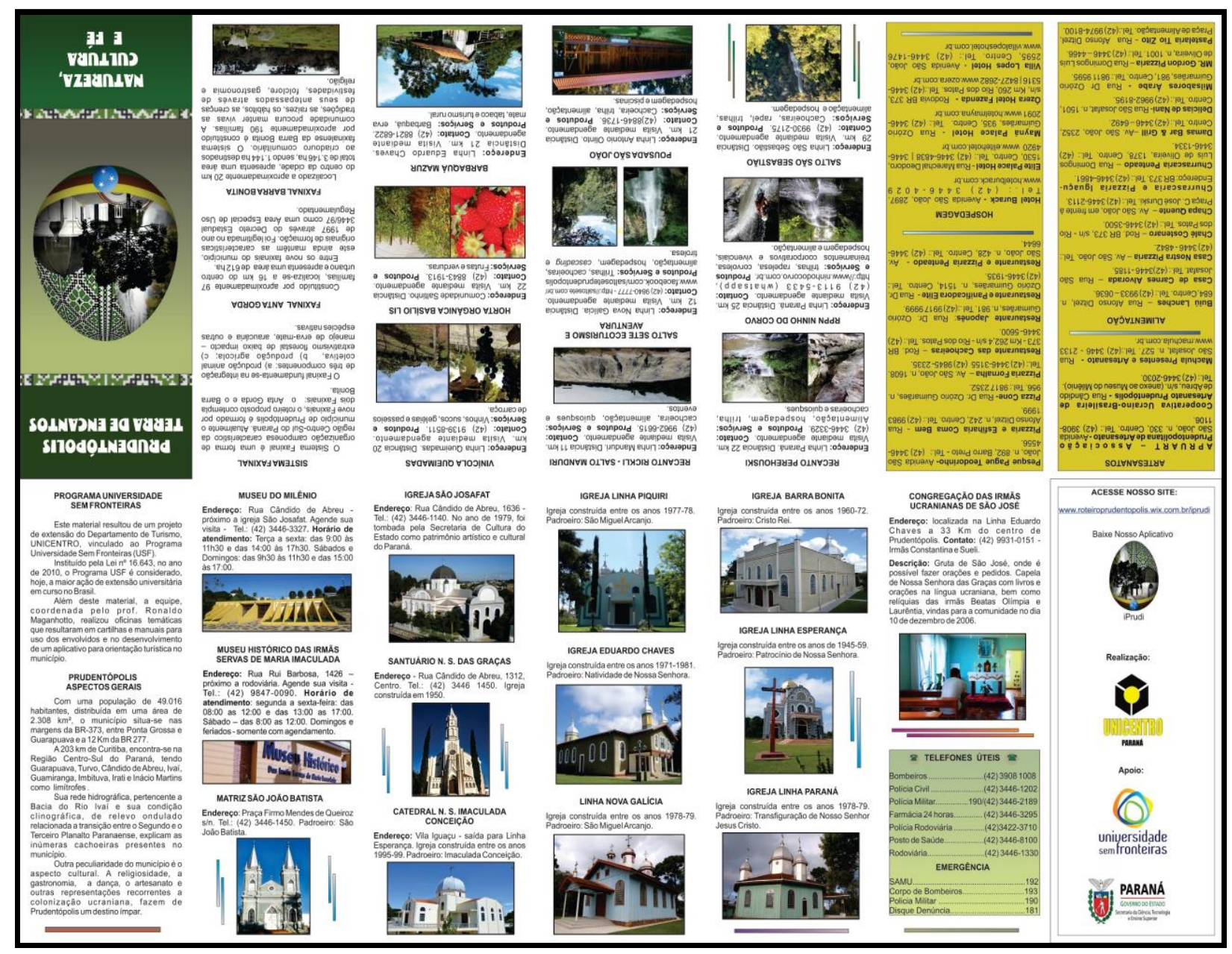

Fonte: desenvolvido pela equipe, 2017. 


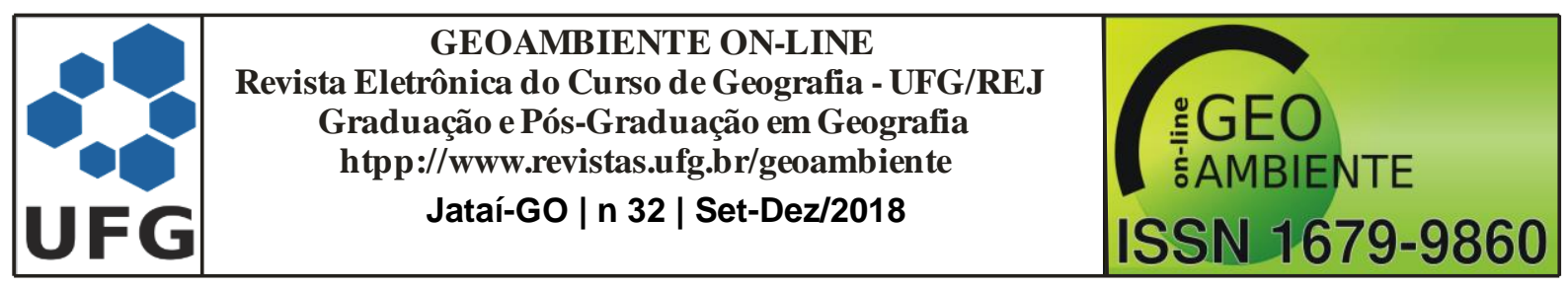

Com informações básicas sobre cada uma das propriedades participantes do projeto de extensão, o folder está aqui apresentado em sua versão sem dobras, trazendo dados como nome do empreendimento, os serviços oferecidos (atividades de aventura, trilhas, refeições, hospedagem), bem como o endereço e meios de contato, tais como telefone, e-mail, site ou página em rede social.

Na parte central do folder (Figura 6), encontra-se o mapa elaborado através da coleta de pontos georreferenciados coletados durante as atividades de campo. Intencionou-se com essa iniciativa, expor um material de fácil visualização e compreensão para que os turistas pudessem utilizar como meio de programação de suas atividades, uma vez que apresentam as principais rotas turísticas do município, envolvendo as cachoeiras gigantes.

Figura 6: Mapa apontando os empreendimentos turísticos envolvidos no projeto de extensão

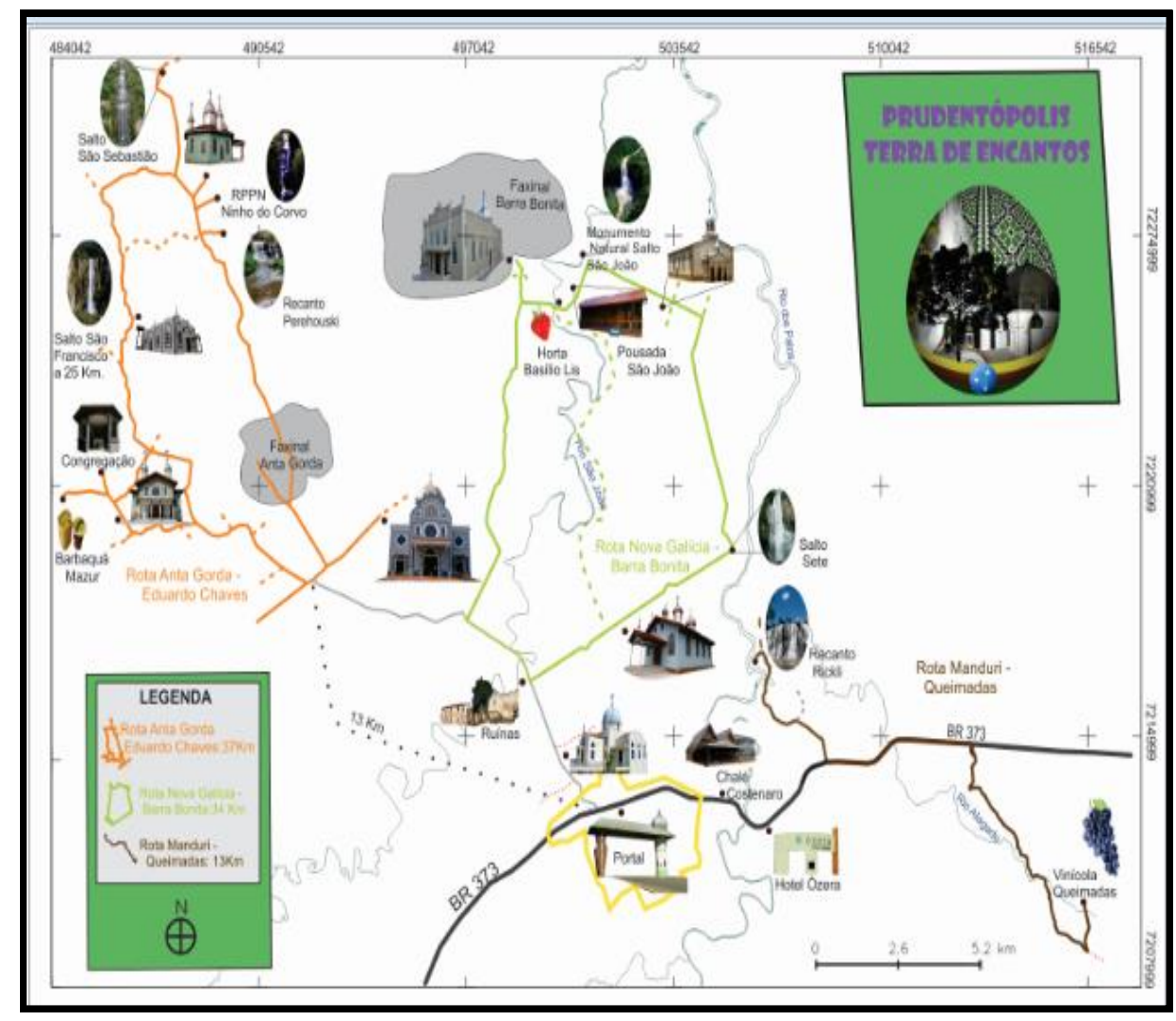

Fonte: desenvolvido pela equipe, 2017.

As rotas foram delineadas com cores distintas, de modo a clarear as informações visuais do mapa, sendo definidas 3 rotas: na cor laranja está a Rota Anta Gorda - Eduardo 


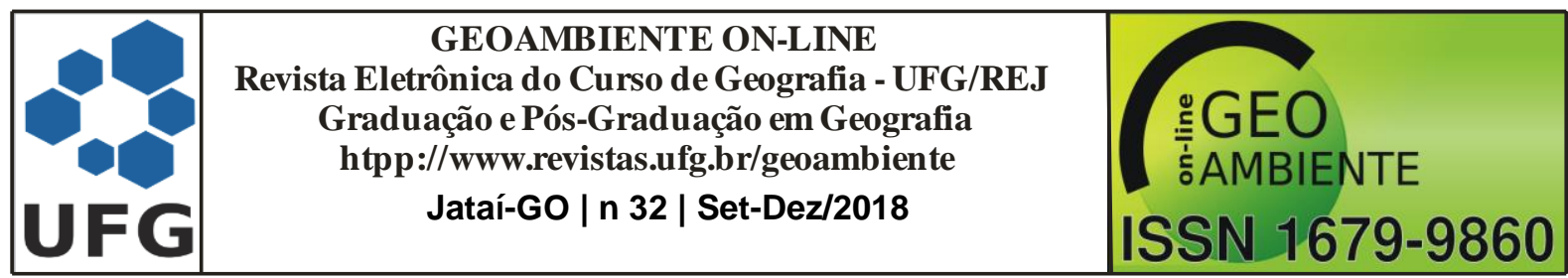

Chaves, que percorre 37 km de estrada de chão abrangendo o Faxinal Paraná Anta Gorda com atrativos naturais se estendo até a Linha Eduardo Chaves, com igrejas ucranianas e cultura preservada. A segunda rota de cor verde, denomina-se Rota Nova Galícia - Barra Bonita contempla $34 \mathrm{~km}$ de estrada, em sua maioria de chão com vasta oferta de cachoeiras, paisagens para contemplação e propriedades rurais que ofertam comida caseira e típica da culinária ucraniana e polonesa.

Por fim, a terceira rota, de cor marrom, encontra-se no outro extremo do município, no sentido Imbituva. A Rota Manduri - Queimadas abrange atrativos como cachoeiras, lanchonete e uma vinícola colonial. Vale a pena ressaltar que o mapa apresentado foi gerado em ambiente de geoprocessamento. O material contempla as coordenadas geográficas, escala e legenda, podendo, assim, ser considerado como um mapa. Este material imprescindível ao visitante/turista, configura-se como ferramenta de extrema importância no planejamento da visita/viagem e de apoio durante o deslocamento em campo.

\section{Iprudi: o aplicativo}

O aplicativo foi desenvolvido para o sistema operacional Android. Isso porque, segundo a International Data Corporation (IDC), esse sistema tem-se mostrado presente na ampla maioria dos smartphones comercializados, dando assim maior alcance para o aplicativo desenvolvido.

Como resultado, tem-se o aplicativo iPrudi, cujo menu principal é exibido na Figura 7. O menu principal divide-se da seguinte forma:

- Início: apresenta a tela principal do aplicativo.

- Natureza: apresenta pontos turísticos naturais.

- Religiosidade e fé: apresenta pontos turísticos religiosos.

- Cultura: apresenta pontos turísticos culturais.

- Rural: apresenta pontos turísticos de cunho rural.

- Hospedagem: apresenta opções de hospedagem.

- Alimentação: apresenta opções de alimentação, como restaurantes.

- Utilidade Pública: apresenta telefones para contato de delegacias, corpo de bombeiros, postos de saúde e terminal rodoviário.

- Condutores e Guias: contatos de taxistas, guia de turismo e turismólogo; 


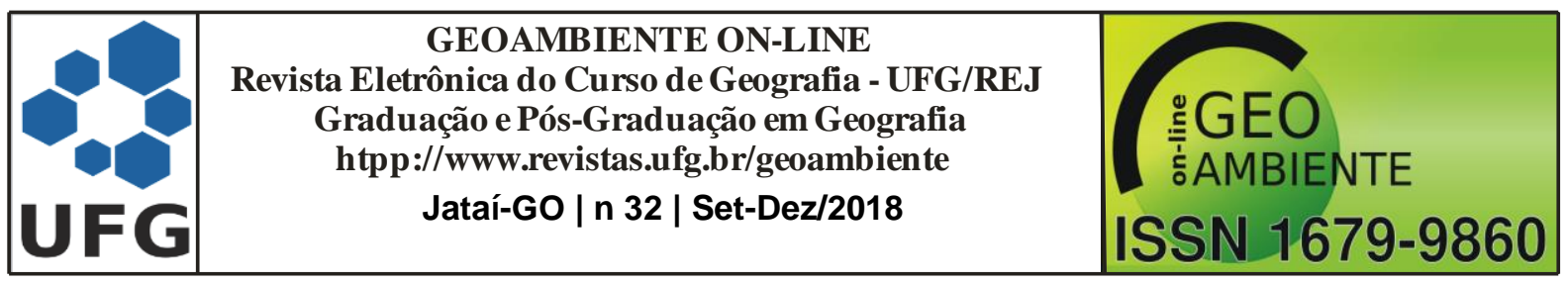

- Informações Extras: pontos de informações turísticas e itens que não se encaixam nas categorias anteriores;

- Equipe: a equipe do projeto no qual o aplicativo se insere;

- Sobre o Aplicativo: informações sobre os desenvolvedores da ferramenta.

Figura 7: Layout da página inicial do Iprudi (A) e uma aba selecionada (B)

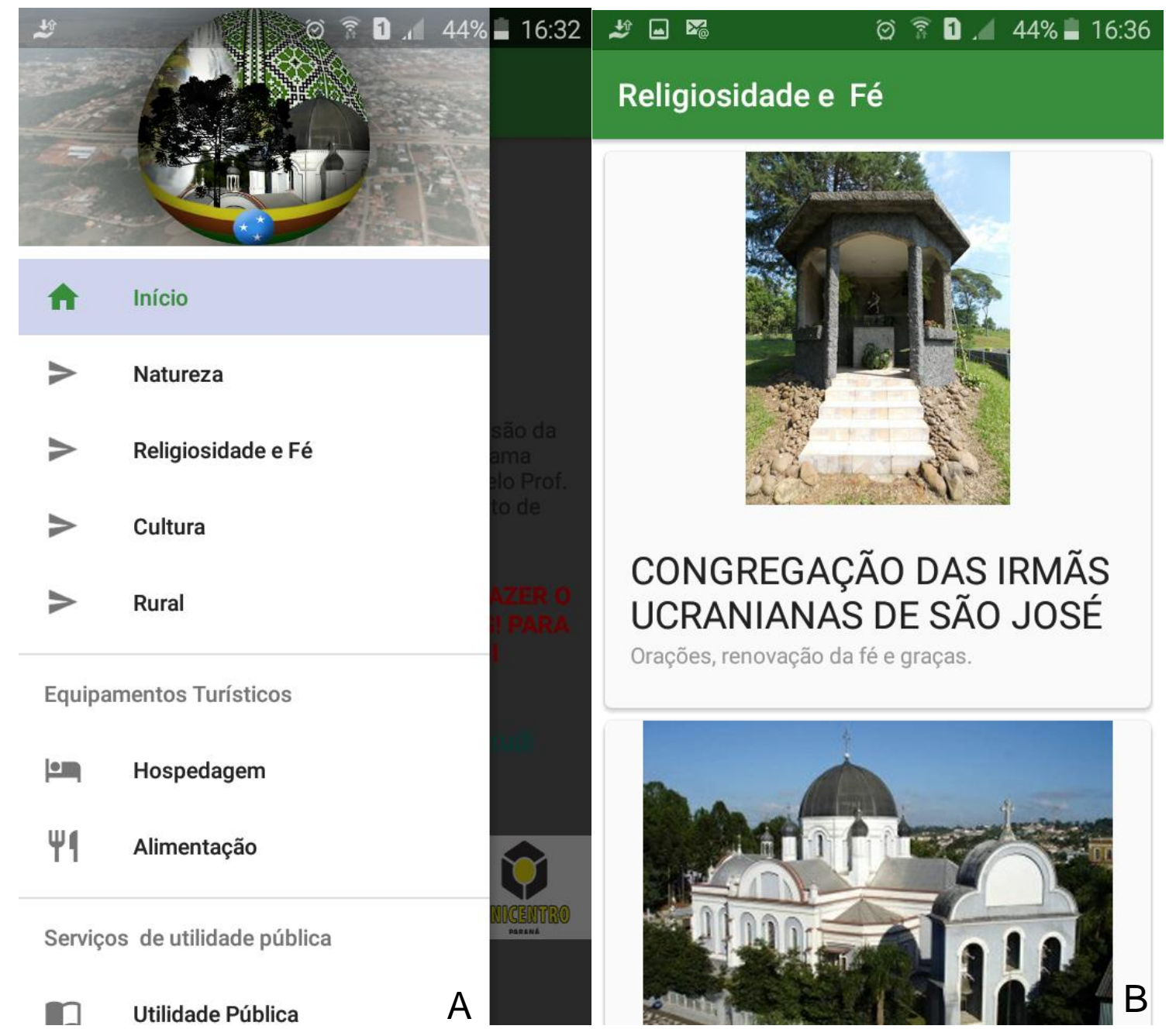

Fonte: Acervo particular dos autores, 2017.

Na bibliografia (BUHALIS; AMARANGGANA, 2015; LAMSFUS, 2015; WANG, XIANG, 2012) ainda não há um consenso sobre quais categorias ou informações um aplicativo necessita conter para adequar-se ao visitante. Algumas experiências relatam depoimentos sobre o que mais os turistas utilizam através de seus smartphones, contudo os 


\begin{tabular}{|c|c|c|}
\hline & $\begin{array}{c}\text { GEOAMBIENTE ON-LINE } \\
\text { Revista Eletrônica do Curso de Geografia - UFG/REJ } \\
\text { Graduação e Pós-Graduação em Geografia } \\
\text { htpp://www.revistas.ufg.br/geoambiente } \\
\text { Jataí-Go | n } 32 \text { | Set-Dez/2018 }\end{array}$ & $\begin{array}{c}\text { ISSN 1679-9860 } \\
\text { G }\end{array}$ \\
\hline
\end{tabular}

resultados são excessivamente pontuais e aplicados em universos que se diferem da realidade brasileira. Assim, tomou-se por base neste produto os parâmetros: "cultura"; "natureza"; "religiosidade"; "ruralidade" e "serviços", entendendo, através da técnica de brainstorming que estes grupos contemplam o perfil turístico do município, perfazendo o círculo proposto pelo Sebrae (2016).

O aplicativo não deve constituir-se como uma versão móvel do site correlato, portanto, todos os atrativos possuem hiperlink com o sistema de posicionamento global por satélite (GPS) que reconhece a localização do usuário e através de direcionamentos automatizados (Google Maps) indica a direção a ser tomada pelo visitante, com indicação visual na tela do smartphone e orientação por voz.

A segunda característica tomada como referência constitui-se de cunho social e de desenvolvimento local. Na aba "serviços", os hotéis, restaurantes, lanchonetes, lojas de artesanatos, souvenirs e a indicação de guias e condutores da região são explanadas. Considerou-se assim, a divulgação, conservação, desenvolvimento sustentável, promoção e garantia de livre concorrência aos envolvidos na cadeia turística.

Ressalta-se que este modelo foi adaptado da bibliografia prévia, por meio de discussões com a equipe multidisciplinar, onde profissionais e estudantes das áreas de Turismo, Geografia, Ciências Contábeis e Engenharia Ambiental submeteram ideias, avaliaram propostas e decidiram por contemplar os elementos aptos à comercialização, apresentando qualidade, acessibilidade, disponibilidade e eficiência para atendimento aos visitantes. Portanto, somente àqueles locais reais tiveram sua inventariação, registro e aprovação, enquanto elementos potenciais foram suprimidos, como estímulo a sua estruturação futura.

As telas possuem o mesmo padrão visual e ao tocar na imagem ou descrição, o usuário é redirecionado para uma página onde são exibidas as seguintes informações sobre o ponto selecionado: nome, endereço, distância partindo da localização atual do usuário, telefone para contato, informações sobre o local e uma integração com a ferramenta Google Maps, onde a rota, partindo da localização atual do usuário e o ponto turístico, é exibida.

\section{Considerações Finais}




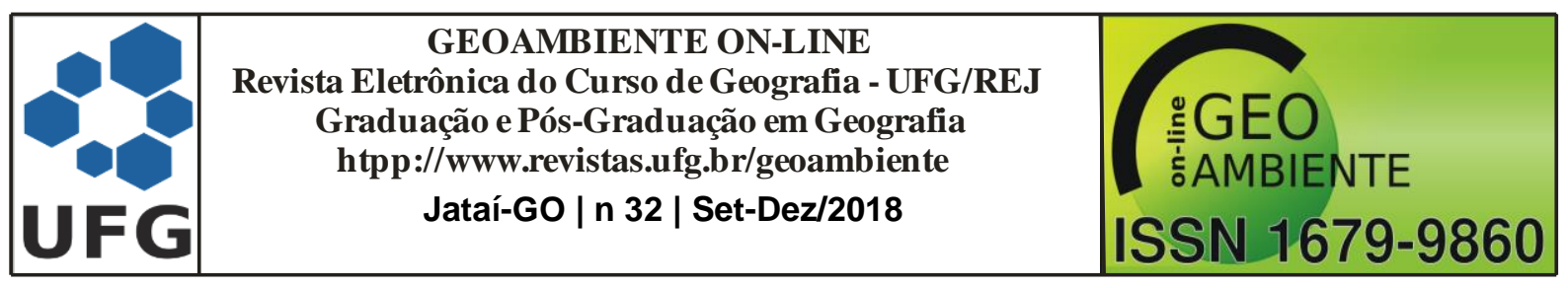

O projeto de extensão aqui apresentado deu origem a alguns produtos de auxílio ao marketing turístico de Prudentópolis. Por meio da criação de um site via plataforma gratuita wix é possível encontrar informações detalhadas de cada uma das propriedades participantes, divididas por segmento: turismo em áreas naturais, religioso, cultural, bem como informações sobre pontos de alimentação, hospedagem, serviços de guias e condutores, além de contatos de emergência.

Complementar ao site, o aplicativo IPrudi traz informações resumidas e um sistema de GPS que permite auxiliar o deslocamento do visitante, guiando por meio de imagens e áudio. Por fim, através do mapa, é possível visualizar as rotas sugeridas e identificar claramente o posicionamento de cada propriedade participante, além das principais cachoeiras do município.

Conclui-se que, os produtos gerados através da execução desse projeto foram de grande valia, contribuiu para o desenvolvimento turístico do município e serviu de base para futuras iniciativas do poder público e privado, que almejam alavancar ainda mais a atividade na região.

\section{Agradecimentos}

Agradecemos à Secretaria da Ciência, Tecnologia e Ensino Superior (SETI), aos empreendimentos turísticos e parceiros de Prudentópolis, aos professores do Instituto Federal do Paraná: Rodrigo Duda e Cleverson dos Anjos, aos alunos Deivid Gobor, Matheus Oleinik e Sofia Suzuki.

\section{Referências}

AFFOLTER, D. The Electronic Tourism Market Place New Challenges. Anais eletrônicos da The 10th International Conference on Information and Communication Technologies in Tourism Istanbul. Turquia, 2003.

ANDROID STUDIO. O IDE oficial do Android. Disponível em: <https://developer.android.com/studio/index.html?hl=pt-br> Acesso em 04 de agosto de 2017. BENI, M. C. Análise Estrutural do Turismo. 10ª Edição. São Paulo: Senac, 2004.

BOULlÓN, R. C. Planificación del espacio turístico. 3. ed. México: Trilhas, 1997 (reimp. 2001). 


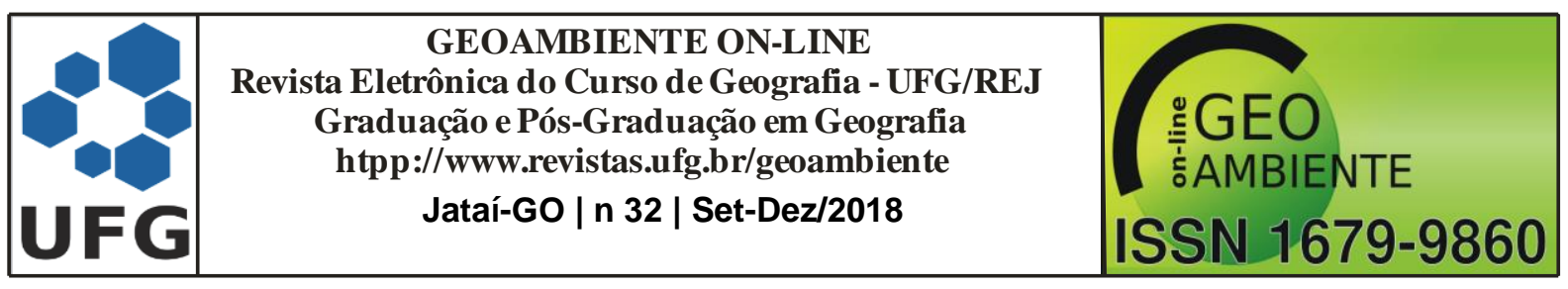

BRASIL. Destinos indutores: Política de desenvolvimento do turismo nos destinos. s/d. Disponível em: <http://www.turismo.gov.br/sites/default/turismo/noticias/acontece/download_acontece/Airto nPereira_Destinos_Indutores_manhx_0408.pdf>. Acesso em 25 de maio de 2018.

BUHALIS, D; AMARANGGANA, A. Smart Tourism Destinations Enhancing Tourism Experience Through Personalisation of Services. In: Information and Communication Technologies in Tourism. Springer, 2015. p. 376-389.

CÂMARA, G.; DAVIS, C.; MONTEIRO, A. M. V. Introdução a Ciência da Geoinformação. São José dos Campos, SP: INPE, 2001.

CONNECTED SMART CITIES. Resultados 2015. Disponível em: <http://www.connectedsmartcities.com.br/index.php/csc-resultados-2015/>. Acesso em 15 $\operatorname{dez} 2016$.

DINIZ, E. Mobilidade no Século XXI. In: CGI.Br - Comitê Gestor da Internet no Brasil. Pesquisa sobre o uso das tecnologias da informação e comunicação nos domicílios brasileiros. São Paulo, 2015. Disponível em: <http://www.cgi.br/media/docs/publicacoes/2/TIC_Domicilios_2014_livro_eletronico.pdf >. Acesso em 10 de dezembro de 2016.

GÂNDARA, J. M. G. Estratégias comunicacionais do destino Curitiba. In: REJOWSKI, M., COSTA, B. K. Turismo contemporâneo: desenvolvimento, estratégia e gestão. São Paulo: Atlas, 2003. pp. 161-170.

HALL, S. A identidade cultural na pós-modernidade. Tradução por Tomaz Tadeu da Silva e Guacira Lopes Louro. 11. ed. Rio de Janeiro: DP \& A, 1999.

HOSTELTUR. Las 20 tendencias tecnológicas que transformarán el turismo. Disponível em: <http://www.hosteltur.com/114480_20-tendencias-tecnologicas transformaranturismo.html>. Acesso em 19 de junho de 2014.

IBGE - Instituto Brasileiro de Geografia e Estatística. Localização do município de Prudentópolis. 2005; In: SILVA, Julio Manoel França da. GÂNDARA, José Manoel Gonçalves. Geotecnologia aplicada à conservação, divulgação e uso de atrativos geoturísticos de Prudentópolis (PR). Revista Brasileira de Ecoturismo. São Paulo, v.7, no 2, maioljulho 2014, pp. 374-393. 


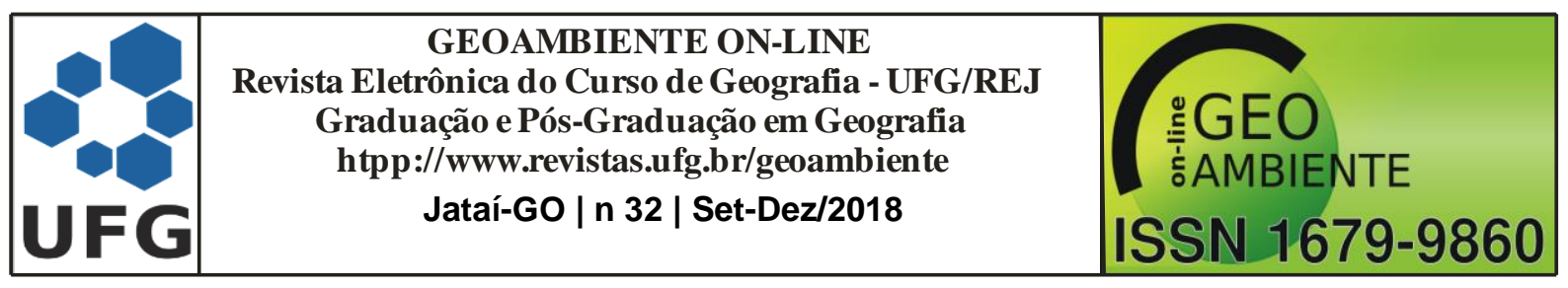

LAMSFUS, C. et al. Smart Tourism Destinations: An Extended Conception of Smart Cities Focusing on Human Mobility. In: Information and Communication Technologies in Tourism 2015. Springer, 2015. p. 363-375.

MUÑOZ, A. L. A; SANCHÉZ, S. G. Destinos Turísticos Inteligentes. Harvard Deusto business review, año 2013, n. 224. p. 61-69.

PATTERSON, T. C. Google Earth as a (Not Just) Geography Education Tool. Journal of Geography. V. 106, issue 4, 2007, p. 145-152.

PREFEITURA MUNICIPAL DE PRUDENTÓPOLIS. Inventário da Oferta Turística. Prudentópolis, 2015.

SEBRAE - Serviço Brasileiro de Apoio às Micro e Pequenas Empresas. Boletim de Inteligência. $2016 . \quad$ Disponível em: <https://www.sebrae.com.br/Sebrae/Portal\%20Sebrae/Anexos/BI_Tur_2016_06_Destinos\%2 0Tur\%C3\%ADsticos\%20Inteligentes.pdf>. Acesso em 10 de dezembro de 2016.

SHEPPARD, S. R. J; CIZEK, P. The ethics of Google Earth: Crossing thresholds from spatial data to landscape visualization. Journal of Environmental Management. V. 90, issue 6, may 2009, p. 2102-2117.

SILVA, J. M. F; GÂNDARA, J. M. G. Geotecnologia aplicada à conservação, divulgação e uso de atrativos geoturísticos de Prudentópolis (PR). Revista Brasileira de Ecoturismo. São Paulo, v.7, nº 2, maioljulho 2014, pp. 374-393.

SOMMERVILLE, I. Software engineering. Pearson. 2011. 773 p.

TRIBUNA PARANÁ. Prudentópolis e suas cachoeiras gigantes. 2008. Disponível em: $<$ http://www.tribunapr.com.br/arquivo/viagem-turismo/prudentopolis-e-suas-cachoeiras gigantes/>. Acesso em 17 de julho de 2017.

WANG, D; XIANG, Z. The new landscape of travel: A comprehensive analysis of smartphone apps. In: Information and Communication Technologies in Tourism 2012. Springer, 2012. p. 308-319.

WEBER, E. J.; HASENACK, H. O uso de SIG no ensino de ciências ambientais. 1999.

Disponível em: <http://www.ecologia.ufrgs.br/labgeo/arquivos/Publicacoes/Congressos/1999/Weber_\&_Has enack_1999_SIG_ensino_ciencias_ambientais.pdf>. Acesso em 20 de setembro de 2017. 


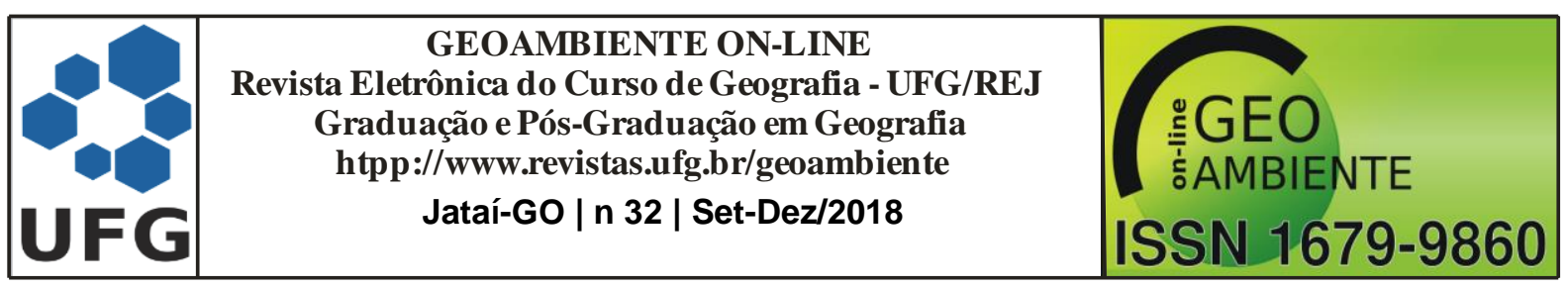

ZAMIR, A. R; SHAH, M. Accurate Image Localization Based on Google Maps Street View. In: Computer Vision - ECCV 2010. 11th European Conference on Computer Visio Heraklion, Crete, Greece, September 5-11, 201, Proceedings, Part IV 